\title{
Esophageal foreign body removal by thoracotomy in a patient with aberrant right subclavian artery
}

\author{
Chi Hoon Bae, Jun Woo Cho
}

Department of Thoracic and Cardiovascular Surgery, School of Medicine, Daegu Catholic University, Daegu, Korea (South)

Kardiochir Torakochir Pol 2020; 17 (4): 212-213

Foreign bodies in the thoracic esophagus can usually be removed by an endoscopist. However, a sharp foreign body placed between large arteries can be difficult and troublesome even for a skilled endoscopist. In such cases, thoracotomy may be required.

A 57-year-old man was referred to our emergency center from a local clinic. After having a fish for his lunch one day before, the patient complained of having sore throat, odynophagia, and substernal chest pain. Emergency gastrofiberscopy revealed a fish bone stuck transversely at the upper thoracic esophagus (Figure 1). There was no retained food material, and neither side of the esophageal wall (piercing site) had signs of inflammation. Chest X-ray did not show any abnormal findings. Chest computed tomography showed a calcified bone located between the aortic arch and an aberrant right subclavian artery which originates from the distal aortic arch distal to the origin of the left subclavian artery. This artery runs under and around the esophagus to the right arm (Figure 2). Laboratory findings were generally normal, except for a slightly elevated white blood cell count $(15,000 / \mu \mathrm{l})$ and C-reactive protein (56 mg/l). Body temperature was normal. As the foreign body removal by an endoscopist was considered difficult

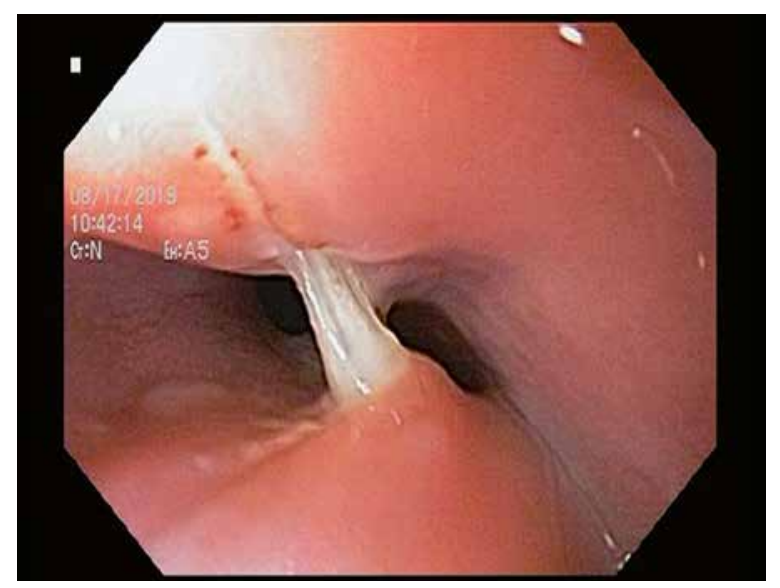

Figure 1. Gastrofiberscopy shows a foreign body placed transversely in the upper thoracic esophagus and dangerous, the patient was referred to a thoracic surgeon for emergent thoracotomy.

The patient was placed in the lateral decubitus position with a double lumen endo-bronchial tube. Right mini-thoracotomy $\left(10 \mathrm{~cm}\right.$ length) was performed through the $4^{\text {th }}$ intercostal space without the $5^{\text {th }}$ rib division. The pleural cavity was entered, and little signs of infection were found. To locate the foreign body, the upper thoracic esophagus was mobilized by making an incision at the mediastinal pleura and dissecting the azygous vein, superior vena cava, and aberrant subclavian artery away from the esophagus. Fortunately, we managed to locate the bone without making an esophagotomy by finger palpation of one end of the fish bone. The bone was successfully pulled out by grabbing the end of the bone with a forceps. The bone was about $3 \mathrm{~cm}$ long and $2 \mathrm{~mm}$ thick with needle-sharp ends (Figure 3). As there were no signs of infection or inflammation, the perforation site was simply closed with a single polydioxanone 4-0 suture. After bleeding control and thorough irrigation, the thorax was closed layer by layer with a chest tube in

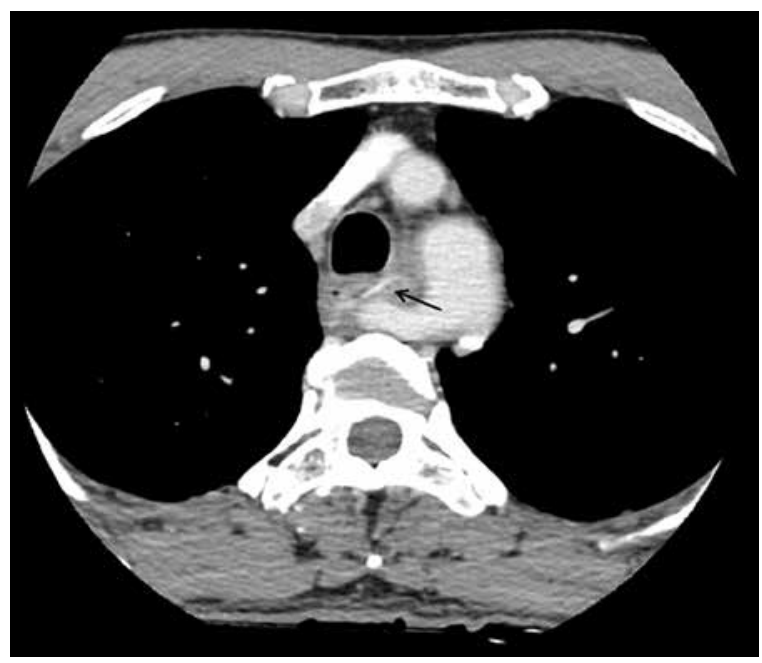

Figure 2. Chest computed tomography scan shows a calcified foreign body in the upper thoracic esophageal lumen between the aortic arch and the aberrant right subclavian artery

Address for correspondence: Chi Hoon Bae MD, Department of Thoracic and Cardiovascular Surgery, School of Medicine, Daegu Catholic University, Daegu, Korea (South), e-mail: chbae71@cu.ac.kr

Received: 22.09.2020, accepted: 16.11.2020. 
place. Oral intake was started 5 days after the operation, and the patient recovered without any complications.

Esophageal perforation (EP) is a rare and potentially life-threatening event with a $20 \%$ survival rate [1]. It may be iatrogenic (most frequently), spontaneous, or caused by trauma, tumors, or foreign bodies. Ingested foreign bodies are responsible for $80 \%$ of cervical perforations and for 9-35\% of all esophageal perforations [2].

Sharp and pointed objects account for a third of all perforations caused by gastrointestinal (GI) foreign bodies, and if untreated, up to $15-35 \%$ of sharp or pointed foreign bodies may lead to a GI complication. The most common inadvertently swallowed sharp foreign bodies are bones, toothpicks, and dental bridgework. Sharp objects are often the most difficult esophageal foreign bodies to remove and may have higher complication rates associated with their removal [3].

Most esophageal foreign bodies occur in young children, but certain populations of adults are also at risk, including those with psychiatric disorders, developmental delays, alcohol use disorder, and incarcerated individuals [4]. Our patient did not have any psychiatric or alcohol problems.

Usually, a fishbone stuck transversely in the esophagus can be removed by a skilled endoscopist by simply fracturing the bone or by exposing one end of the bone by gently pushing the other end toward the wall of the esophagus. However, in our case, this maneuver could be dangerous and harmful, as the sharp bone was placed transversely between the aberrant right subclavian artery on the right side and the aortic arch on the left side, thereby leaving the possibility of injuring either of the arteries during manipulation.

We assumed that esophagotomy was needed to remove the bone. However, in the operative field, after the dissection of the esophagus from the aberrant right subclavian artery and the aorta, we managed to locate one end of the sharp bone by finger palpation. Esophageal dissection was done carefully not to migrate the bone and hence injure the vessels. We successfully managed to remove the fishbone without esophagotomy by simply grabbing the protruding end of the bone and pulling it out with a forceps.

In many cases of esophageal perforation, mediastinitis can result in diverse management situations depending on the duration and severity of the inflammation. For instance, Ugenti et al. reported a successfully managed case with a perforation at both walls of the esophagus by an animal

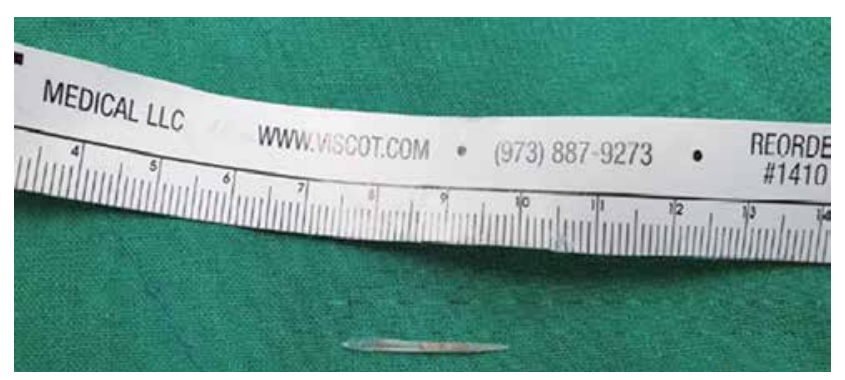

Figure 3. The removed fish bone showing needle sharp ends on both sides $(25 \times 2 \mathrm{~mm})$

bone by a combined endoscopic and surgical approach. In this way, it was possible to easily detect the location of the perforation, safely remove the foreign body, repair the perforation both from the outside and from the inside, and place the nasogastric tube under direct vision [5]. If the fishbone had not been palpable in our case, this combined approach could have been considered as an alternative procedure to remove the fishbone rather than esophagotomy.

Although most sharp foreign body impactions in the esophagus can be managed by a skilled endoscopist, difficult cases can be managed by a skilled surgeon by emergent thoracotomy or by a combined approach. Therefore, when handling high-risk patients with the risk of esophageal perforation or large vessel injuries, emergency medical doctors and endoscopists should urgently seek the assistance of a surgeon.

\section{Disclosure}

The authors report no conflict of interest.

\section{References}

1. Patrick RP. Techniques in Gastrointestinal Endoscopy 2014; 16: 32-39.

2. Chirica M, Champault A, Dray X, Sulpice L, Munoz-Bongrand N, Sarfati E, Cattan P. Esophageal perforations. J Visc Surg 2010; 147: e117-e128.

3. Long B, Koyfman A, Gottlieb M. Esophageal foreign bodies and obstruction in the emergency department setting: an evidence-based review. J Emerg Med 2019; 56: 499-511.

4. Ikenberry SO, Jue TL, Anderson MA, Appalaneni V, Banerjee S, Ben-Menachem T, Decker GA, Fanelli RD, Fisher LR, Fukami N, Edwyn Harrison M, Jain R, Khan KM, Krinsky ML, Maple JT, Sharaf R, Strohmeyer L, Dominitz JA. Management of ingested foreign bodies and food impactions. Gastrointest Endosc 2011; 13: 1085-1091.

5. Ugenti I, Digennaro R, Martines G, lambrenghi OC. Double esophageal perforation by ingested foreign body: Endoscopic and surgical approach: a case report. Int J Surg Case Rep 2015; 17: 55-57. 